\title{
Negative Association of Plasma Levels of Vitamin D and miR-378 With Viral Load in Patients With Chronic Hepatitis B Infection
}

\author{
Ashraf Mohamadkhani ${ }^{1}$; Faegh Bastani ${ }^{1}$; Samaneh Khorrami ${ }^{1}$; Reza Ghanbari ${ }^{1}$; Sareh \\ Eghtesad ${ }^{1}$; Maryam Sharafkhah ${ }^{1}$; Ghodratollah Montazeri ${ }^{1}$; Hossein Poustchi ${ }^{1,}$ \\ ${ }^{1}$ Liver and Pancreatobiliary Diseases Research Center, Digestive Diseases Research Institute, Tehran University of Medical Sciences, Tehran, IR Iran \\ ${ }^{*}$ Corresponding Author: Hossein Poustchi, Liver and Pancreatobiliary Diseases Research Center, Digestive Diseases Research Institute, Tehran University of Medical Sciences, Tehran, \\ IR Iran. Tel: +98-2182415141, Fax:+98-2182415400, E-mail: h.poustchi@gmail.com
}

Received: February 28, 2015; Revised: April 25, 2015; Accepted: April 28, 2015

\begin{abstract}
Background: Chronic Hepatitis B (CHB) is accompanied by inflammation of liver because of infection with Hepatitis B Virus (HBV) Previous studies revealed an inverse association between vitamin D and HBV DNA levels.

Objectives: The current study aimed to investigate the levels of $25(\mathrm{OH}) \mathrm{D} 3$ (the steady form of vitamin D), miR-378 and HBV DNA in the patients with CHB.

Patients and Methods: One hundred and seventy three patients with HBeAg negative CHB were recruited for the study. Plasma levels of HBVDNA and $25(\mathrm{OH})$ D3 were quantified. The expression level of miR-378 in plasma was measured by a relative quantitative Real Time Polymerase Chain Reaction (qRT-PCR) assay.

Results: In the pathway regression analysis, the plasma level of $25(\mathrm{OH}) \mathrm{D} 3$ showed a significant inverse correlation with plasma levels of HBV DNA $(-0.198, \mathrm{P}=0.008)$ and direct correlation with miR-378 $(0.188, \mathrm{P}=0.013)$. Similarly plasma level of miR-378 had inverse association with HBV DNA level $(-0.177, \mathrm{P}=0.020)$.

Conclusions: These results suggest that vitamin D could involve in a miRNA-mediated regulatory pathway in control of HBV replication. Further studies are recommended to understand the effects of miR-378 and anti-infective action of vitamin D on Hepatitis B Virus.
\end{abstract}

Keywords: Chronic Hepatitis B; Hepatitis B Virus; Vitamin D; miR-378

\section{Background}

Human Hepatitis B Virus (HBV) is the prototype for a family of viruses referred as the hepadnaviridae. These viruses infect hepatocytes, the only confirmed site of replication for all members of this family $(1,2)$. Chronic Hepatitis $\mathrm{B}(\mathrm{CHB})$ is an ongoing serious infection that causes the development of necroinflammatory liver disease and subsequent fluctuation in liver enzyme levels. To be diagnosed with $\mathrm{CHB}$, a titer of hepatitis B surface Antigen (HBsAg) is measured and often patients have detectable serum HBV DNA, while the hepatitis B e antigen while HBeAg (the extracellular form of HBcAg) is usually absent $(3,4)$. Resolution of the HBV infection is mainly related to the interplay between the virus and the complex interactions between host innate and adaptive immune responses (2). Antiviral immunity is strongly associated with the function of plasmacytoid dendritic cells (pDCs) and natural killer or NK cells as the first line defense and non-specific immune responses $(5,6)$. In addition, a polyclonal strong response of T-helper 1 (Th1) and cytotoxic Tlymphocytes (CTL) imply that the clearance of HBV infection occurs through an adaptive immune response $(4,7)$.
MicroRNAs (miRNAs) principally control the mammalian immune system $(8,9)$. Several studies are conducted to identify and characterize the miRNAs dysregulated in the HBV related liver cancer (10-12). The miRNAs are short non-coding RNAs resistant to endogenous RNase activity. They regulate gene expression post-transcriptionally either by degradation of target mRNA transcripts or suppression of mRNA translation (13). The miRNAs represent key factors in cancer development, since they regulate the expression of central tumor suppressor genes and oncogenes (14). The importance of miRNAs in the development and function of the immune system is previously shown (9). Based on the findings, alterations in the expression of some specific miRNAs are linked to the bioactive metabolite of vitamin D. For instance, DCs treated by vitamin $\mathrm{D}$, showed an over-expression of miR-378 (15). The biologically active metabolite of vitamin $\mathrm{D}, 1 \alpha$, 25-Dihydroxyvitamin D3 $\left(1,25(\mathrm{OH})_{2} \mathrm{D}_{3}\right)$, with its antiinflammatory and anti-tumor function, mediates the innate and adaptive immune responses of the body to infectious diseases and tumors $(16,17)$. Besides its calci-

Copyright (C) 2015, Kowsar Corp. This is an open-access article distributed under the terms of the Creative Commons Attribution-NonCommercial 4.0 International License (http://creativecommons.org/licenses/by-nc/4.0/) which permits copy and redistribute the material just in noncommercial usages, provided the original work is properly cited. 
um and bone homeostasis activity, vitamin D also regulates the transcription of vitamin $\mathrm{D}$ responsive genes in various types of cells by activating the vitamin $D$ receptor (VDR). These receptors are over expressed in popular cells of the immune system (18). One of the main targets of $1,25(\mathrm{OH})_{2} \mathrm{D}_{3}$, are dendritic cells (DCs), the professional Antigen Presenting Cells (APCs) that capture antigens to process and present them to $\mathrm{T}$ cells. It is reported that $1,25(\mathrm{OH})_{2} \mathrm{D}_{3}$ decreases the stimulatory capacities of DCs in the activation of T cells, via downstream VDR signaling pathway that prevents excessive inflammation (19). Further evidence also supports its role in the modulation of innate immunity, through the reduction of DC markers and DC-derived cytokine levels, and greater expression of IL-10 (16). Recent studies show the influence of vitamin $\mathrm{D}$ on clinical outcomes and spontaneous HBsAg seroclearance in CHB patients $(20,21)$. Earlier reports also showed an antagonistic relationship between baseline serum vitamin D status and HBV DNA levels (20).

\section{Objectives}

The exact mechanism by which vitamin $\mathrm{D}$ achieves an anti-viral response in CHB is still undefined. Regarding the effect of vitamin D on the expression of miR-378 in DCs, the current study aimed to assess the association of plasma miR-378 and vitamin D levels with clinical and virological parameters in the patients with CHB.

\section{Patients and Methods}

One hundred and seventy three patients with normal to elevated ALT levels of HBeAg negative CHB, visited in the Hepatitis Clinic of Shariati Hospital, Tehran, Iran, were recruited for the current study. All patients had prenatally acquired $\mathrm{CHB}$, since they had a clear history of familial $\mathrm{HBV}$ infection with the presence of HBsAg. The study only included naive patients with CHB. Prior to performing a liver biopsy, demographic data were gathered and plasma samples were collected from all patients and stored at $-70^{\circ} \mathrm{C}$ until subsequent analysis. Histology was graded using the modified HAI (histological activity index) scoring system (22). The total HAI score is comprised of the necroinflammation grade and score of fibrosis. The study was approved by the Clinical Research Ethics Committee of Shariati Hospital affiliated to Tehran University of Medical Sciences.

\subsection{Quantification of $25(\mathrm{OH}) \mathrm{D} 3$ in the Patients' Plasma}

The levels of $25(\mathrm{OH}) \mathrm{D} 3$ in the patients' plasma, as the most stable form of vitamin D in the body, were measured to indicate vitamin $\mathrm{D}$ status in the individuals, using an Enzyme-Linked Immunosorbent Assay (ELISA) kit (EUROIMMUN, Lubeck; Germany) following the manufacturer's instructions. Plasma $25(\mathrm{OH})$ D3 levels of $<20$ and $<10 \mathrm{ng} / \mathrm{mL}$ were considered as insufficiency and deficiency, respectively, whereas concentrations $\geq 20 \mathrm{ng} / \mathrm{mL}$ were considered as adequate.

\subsection{Quantification of HBV DNA}

The plasma levels of HBV DNA were quantified by LightCycler software version 3.5 (Roche Applied Science, Mannheim, Germany) using the RealARTTM HBV LC PCR (QIAGEN, Hilden, Germany) according to the manufacturer's instructions (23) with a detection limit of 50 copies $/ \mathrm{mL}$.

\subsection{Plasma miR-378 Quantification}

\subsubsection{Total RNA Isolation and cDNA Synthesis}

Extraction of total RNA, including small RNA from plasma samples, was carried out using the TRIzol LS Reagent (Invitrogen, UK) according to the manufacturer's protocol. The extracted RNA was eluted in $20 \mu \mathrm{L}$ of elution buffer and the quality of RNA was measured using the NanoDrop-2000 Spectrophotometer (Thermo Fisher Scientific Inc, Wilmington, DE, USA). The range of extracted RNA was from 20 to $50 \mathrm{ng} / \mu \mathrm{L}$. Reverse transcription (RT) was performed using the miScript Reverse Transcription kit (QIAGEN, Germany), following protocol based on commercial kit.

\subsection{Real-Time Quantitative Polymerase Chain Re- action}

The selected miRNA, miR-378, was amplified with primer "miR-378: ACTGGACTTGGAGTCAGAAGG" based on the miRNA sequences obtained from the miRBase database (24). Real-time PCR was performed on LightCycler software version 3.5 (Roche Applied Science, Mannheim, Germany) using the miScript SYBR Green PCR kit (Qiagen, Germany). The miR-1228 was used as an endogenous control for normalization (25). The Relative quantification of miR-378 in real-time RT-PCR was calculated using the cycle threshold $(\mathrm{Ct})$ values and evaluated by the $2-\Delta \mathrm{Ct}$ method [20], where $\Delta \mathrm{Ct}$ was calculated by deducting the Ct values of miR-1228 from the $\mathrm{Ct}$ values of the selected miRNA.

\subsection{Statistical Analyses}

All statistical analyses were performed using the R 3.0.2 statistical software. Characteristics of the subjects were presented as means with standard deviation (SD) and medians with Inter Quartile Ranges (IQR). Associations between the variables were assessed by Spearman's rank correlation. Path regression analysis was used to detect any direct and indirect effects of $25(\mathrm{OH})$ D3 on both HBV DNA and miR-378 expression. Chi-square test to assess the model's goodness of fit (GOF). AP value $<0.05$ was considered statistically significant. 


\section{Results}

\subsection{Demographic and Clinical Characteristics of} Subjects

A total of 173 subjects, 118 (68\%) males and 55 (32\%) females, with HBV-related chronic hepatitis, were included in the study. The mean (SD) age of the subjects was $37 \pm$ 9.7 years with the range of 21 to 62 . Clinical characteristics of the subjects are summarized in Table 1 . The mean plasma concentrations of $25(\mathrm{OH}) \mathrm{D} 3$ was $22.19(8.28) \mathrm{ng} /$ mL. Of the 173 subjects, 5 (3\%), 67 (39\%), and 101 (58\%) had vitamin D deficiency, insufficiency, and adequacy, respectively. The expressions of miR-378 were measured by Real time qRT-PCR in plasma samples of all subjects against miR-1228 as a housekeeping control. The mean value (SD) of the miR-378 expression was calculated by the $2-\Delta \mathrm{Ct}$ formula, which was $6.22 \pm 9.99$.

\subsection{The Relationship Between Plasma Levels of HBV DNA, $25(\mathrm{OH})$ D3 and Mir-378}

There was a significant, inverse correlation between plasma levels of log $10 \mathrm{HBV}$ DNA (copies/mL) and both $25(\mathrm{OH}) \mathrm{D} 3(\mathrm{r}=-0.32, \mathrm{P}<0.001)$ (Figure 1) and miR-378 $(\mathrm{r}$ $=-0.24, \mathrm{p}=0.002)$. There was also a positive correlation between plasma levels of $25(\mathrm{OH}) \mathrm{D} 3$ and miR-378 $(\mathrm{r}=0.18$, $\mathrm{P}=0.021)$. HBV DNA was also significantly correlated with ALT levels $(r=0.36, \mathrm{P}<0.001)$ and the total HAI score $(\mathrm{r}=$ $0.35, \mathrm{P}<0.001)$. In addition, a significant correlation was found between the total HAI score and age $(\mathrm{r}=0.18, \mathrm{P}=$ $0.015)$, as well as ALT levels ( $\mathrm{r}=0.43 \mathrm{P}<0.001)$. However HAI score showed a negative association trend with 25 $(\mathrm{OH}) \mathrm{D} 3$ plasma level $(\mathrm{r}=-0.128, \mathrm{P}=0.092)$.

The effect of $25(\mathrm{OH})$ D3 on HBV DNA level was directly and indirectly analyzed through miR-378 expression. In order to reach the model's goodness of fit, the direct effect of $25(\mathrm{OH}) \mathrm{D} 3$ and miR-378 plasma levels were adjusted for age and gender on HBV DNA levels. The p-value for the chi-square GOF was 0.803 .

The results are shown in Table 2 and they revealed that $25(\mathrm{OH})$ D3 had a significant inverse, and positive effect
Table 1. Clinical Characteristics of the Patients With $\mathrm{CHB}^{\mathrm{a}}$

\begin{tabular}{lcc}
\hline & Mean \pm SD & Median $($ IQR) \\
\hline Age, $\mathbf{y}$ & $37 \pm 9.7$ & $36(21-62)$ \\
$\mathbf{2 5}(\mathbf{O H}) \mathbf{D 3}, \mathbf{n g} / \mathbf{m L}$ & $22.19 \pm 8.28$ & $20(16-27)$ \\
miR-378, RQ & $6.22 \pm 9.99$ & $2(1-8)$ \\
\hline ALT, U/L & $36.81 \pm 10.17$ & $36(29-41)$ \\
HIA score & $4.60 \pm 2.81$ & $4(3-6)$ \\
\hline Log 10 HBV DNA, copies/mL & $3.94 \pm 1.08$ & $3.92(3.20-4.62)$ \\
\hline
\end{tabular}

a Abbreviations: ALT, alanine transaminase; and IQR, inter quartile range.

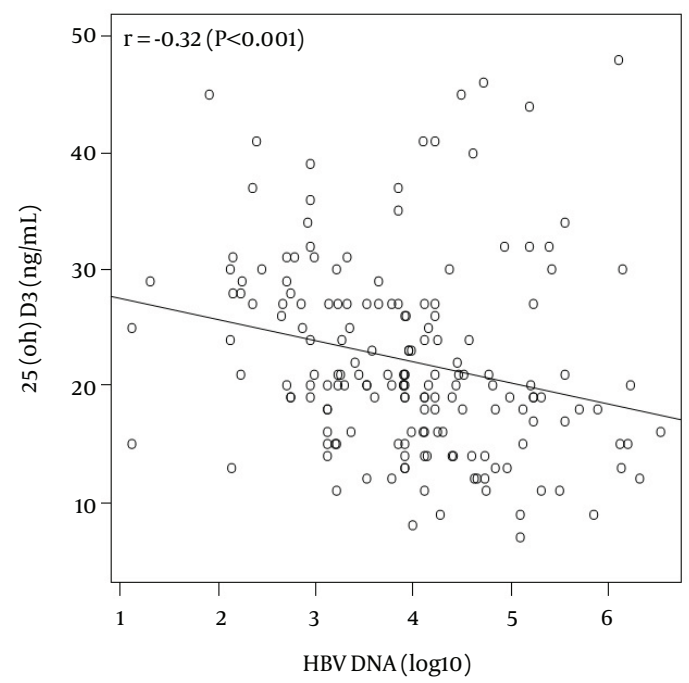

Figure 1. The Correlation Between 25 (OH) D3 and Log 10 HBV DNA (copies) $\mathrm{mL}$ ) Levels in Plasma by Regression Line in Scatter Plot

on HBV DNA (- 0.198, P = 0.008) and miR-378 (0.188, P = $0.013)$, respectively. On the other hand, plasma levels of miR-378 had a significant effect on HBV DNA levels ($0.177, \mathrm{P}=0.020)$. The indirect effect of $25(\mathrm{OH}) \mathrm{D} 3$ on HBV DNA levels, through miR-378, was insignificant $(-0.13, \mathrm{P}=$ 0.087); however the total effect of $25(\mathrm{OH}) \mathrm{D} 3$ on HBV DNA levels showed a significant negative association (- 0.24, P $=0.002$ ).

Table 2. Pathway Regression Analysis

\begin{tabular}{lccc}
\hline & Beta $(\mathbf{9 5} \% \mathbf{C I})$ & Standardized Beta & P Value \\
\hline Factor associated with HBV DNA & & & 0.008 \\
\hline 25(OH) D3 & $-0.026(-0.045--0.007)$ & -0.198 & 0.020 \\
miR-378 expression & $-0.019(-0.034--0.003)$ & -0.177 & 0.401 \\
\hline Age & $0.007(-0.009-0.023)$ & 0.064 & 0.843 \\
\hline Gender, female as reference & $0.034(-0.298-0.365)$ & 0.015 & 0.013 \\
\hline Factor associated with miR-378 & & 0.188 & \\
\hline 25 (OH) D3 & $0.223(0.046-0.400)$ & & \\
\hline
\end{tabular}




\section{Discussion}

The current study assessed the association of plasma miR-378 and vitamin D levels with clinical and virological parameters in patients with CHB. The results demonstrated that the replication of $\mathrm{HBV}$ is limited in patients with adequate levels of vitamin $\mathrm{D}$, consistent with previous studies $(20,26)$.

The prolonged replication of HBV during CHB could be the main factor to develop cirrhosis and hepatocellular carcinoma (HCC) (27). On the other hand, the anti-inflammatory and immune-modulatory properties of vitamin D suggest its possible role to reduce the severity of chronic hepatitis (26). The beneficial effects of vitamin D in patients with $\mathrm{CHB}$ are highlighted in a study by Farnik et al. (20), although no association between vitamin D and serum HBsAg levels were observed. The evidence revealed that other mechanisms such as an immune-mediated expression of specific miRNAs may contribute to lower replications of $\mathrm{HBV}(11)$. There is a significant relationship between vitamin $D$ and miRNAs, explaining the impact of vitamin D metabolites on the expression of specific miRNAs $(8,15)$.

In the current study it was observed that miR-378 had a rather negative association with HBV DNA. Previous studies had shown an alteration in a large number of miRNAs in chronic hepatitis as well as hepatitis-positive liver tumor specimens $(11,14)$. They found that increased levels of certain miRNAs may be a general response to cellular stress induced by hepatitis and its related liver disorders (cirrhosis, HCC, etc.). Based on these studies serum miR-96, miR-18a, miR-10b, miR-125a, and miR-378 were potential markers of HCC, of which miR-18a was up-regulated, while miR-378 was down-regulated during the course of HCC $(10,11)$. In this regard, another studies reported that miR-378, which involves in cell growth and survival, significantly increased during vitamin D treatment of APCs $(19,28)$, and similar to DCs, the major APCs, miR-378 is the primary cellular target and mediator of the immunomodulatory effects of $1,25(\mathrm{OH})_{2} \mathrm{D}_{3}$; therefore, a possible link between these variables is suggested. Pedersen et al. (19) showed that 1, $25(\mathrm{OH})_{2} \mathrm{D}_{3}$ modulates the activation and survival of DC leading to the hyporesponsiveness of T-cells. Furthermore it was demonstrated that VDR signaling pathways in APC activity and T-cell-stimulatory capacities diminished by vitamin D (17). Dendritic cells lacking stimulatory molecules become tolerogenic and give rise to regulatory T-cells or even induce T-cell anergy $(6,29)$. The current study found that patients with lower HAI scores have higher levels of vitamin D. Although this finding was not significant, it was in agreement with the published studies that contribute to the anti-inflammatory activities of vitamin $\mathrm{D}(8,26)$. Active inflammation appears to be the driving force to develop fibrosis and is prominent during immune-mediated viral clearance. Accordingly the function of vitamin D in innate and adaptive im- mune systems emphasizes the benefits of maintaining adequate levels of this vitamin.

In summary, the study showed a significant inverse relationship between vitamin D levels and HBV replication in patients with chronic infection. The study looked for a unique miRNA "miR-378" in patients with CHB plasma, showing increased expression with higher vitamin D levels, also leading to decreased HBV replication. These finding support the effect of vitamin D on HBV DNA replication. However additional studies on patients with advanced liver fibrosis and those with high ALT levels are necessary to evaluate the potential effect of vitamin D-mediated prevention of viral replication and also the role of miRNAs in vitamin D functions.

\section{Acknowledgements}

Authors wish to express their gratitude to all patients who attended in the research program.

\section{Funding/Support}

This study was supported by grants from the Digestive Diseases Research Institute, Tehran University of Medical Sciences, Tehran, IR Iran.

\section{References}

1. Fattovich G, Bortolotti F, Donato F. Natural history of chronic hepatitis B: special emphasis on disease progression and prognostic factors. J Hepatol. 2008;48(2):335-52.

2. Shoaei SD, Sali S, Karamipour M, Riahi E. Non-invasive histologic markers of liver disease in patients with chronic hepatitis B. Hepat Mon. 2014;14(2):e14228.

3. Brunetto MR, Oliveri F, Colombatto P, Moriconi F, Ciccorossi P, Coco B, et al. Hepatitis B surface antigen serum levels help to distinguish active from inactive hepatitis $\mathrm{B}$ virus genotype $\mathrm{D}$ carriers. Gastroenterology. 2010;139(2):483-90.

4. Mohamadkhani A, Katoonizadeh A, Poustchi H. Immune-Regulatory Events in the Clearance of HBsAg in Chronic Hepatitis B: Focuses on HLA-DP. Middle East J Dig Dis. 2015;7(1):5-13.

5. Zare-Bidaki M, Tsukiyama-Kohara K, Arababadi MK. Toll-like receptor 4 and hepatitis B infection: molecular mechanisms and pathogenesis. Viral Immunol. 2014;27(7):321-6.

6. Moradzadeh M, Tayebi S, Poustchi H, Sayehmiri K, Shahnazari P, Naderi E, et al. The Possible Role of TLR2 in Chronic Hepatitis B Patients with Precore Mutation. Adv Virol. 2013;2013:780319.

7. Bocher WO, Galun E, Marcus H, Daudi N, Terkieltaub D, Shouval $D$, et al. Reduced hepatitis B virus surface antigen-specific Th1 helper cell frequency of chronic HBV carriers is associated with a failure to produce antigen-specific antibodies in the trimera mouse. Hepatology. 2000;31(2):480-7.

8. Li YC, Chen Y, Liu W, Thadhani R. MicroRNA-mediated mechanism of vitamin D regulation of innate immune response.J Steroid Biochem Mol Biol. 2014;144 Pt A:81-6.

9. Xiao C, Rajewsky K. MicroRNA control in the immune system: basic principles. Cell. 2009;136(1):26-36.

10. Li L, Guo Z, Wang J, Mao Y, Gao Q. Serum miR-18a: a potential marker for hepatitis B virus-related hepatocellular carcinoma screening. Dig Dis Sci. 2012;57(11):2910-6.

11. Zhang X, Hou J, Lu M. Regulation of hepatitis B virus replication by epigenetic mechanisms and microRNAs. Front Genet 2013;4:202.

12. Mohamadkhani A. Long Noncoding RNAs in Interaction With RNA Binding Proteins in Hepatocellular Carcinoma. Hepat Mon. 2014;14(5):e18794. 
13. Bartel DP. MicroRNAs: genomics, biogenesis, mechanism, and function. Cell. 2004;116(2):281-97.

14. Murakami Y, Yasuda T, Saigo K, Urashima T, Toyoda H, Okanoue T, et al. Comprehensive analysis of microRNA expression patterns in hepatocellular carcinoma and non-tumorous tissues. Oncogene. 2006;25(17):2537-45.

15. Mohri T, Nakajima M, Takagi S, Komagata S, Yokoi T. MicroRNA regulates human vitamin $\mathrm{D}$ receptor. Int $J$ Cancer. 2009;125(6):1328-33.

16. Gregori S, Giarratana N, Smiroldo S, Uskokovic M, Adorini L. A 1alpha,25-dihydroxyvitamin $\mathrm{D}(3)$ analog enhances regulatory T-cells and arrests autoimmune diabetes in NOD mice. Diabetes. 2002;51(5):1367-74.

17. Hewison M. Vitamin D and immune function: autocrine, paracrine or endocrine? Scand J Clin Lab Invest Suppl. 2012;243:92-102.

18. Carlberg C, Campbell MJ. Vitamin D receptor signaling mechanisms: integrated actions of a well-defined transcription factor. Steroids. 2013;78(2):127-36.

19. Pedersen AW, Holmstrom K, Jensen SS, Fuchs D, Rasmussen S, Kvistborg P, et al. Phenotypic and functional markers for 1alpha,25-dihydroxyvitamin $\mathrm{D}(3)$-modified regulatory dendritic cells. Clin Exp Immunol. 2009;157(1):48-59.

20. Farnik H, Bojunga J, Berger A, Allwinn R, Waidmann O, Kronenberger B, et al. Low vitamin D serum concentration is associated with high levels of hepatitis B virus replication in chronically infected patients. Hepatology. 2013;58(4):1270-6.

21. Fedirko V, Duarte-Salles T, Bamia C, Trichopoulou A, Aleksandrova K, Trichopoulos D, et al. Prediagnostic circulating vitamin D levels and risk of hepatocellular carcinoma in European populations: a nested case-control study. Hepatology. 2014;60(4):1222-30.

22. Ishak K, Baptista A, Bianchi L, Callea F, De Groote J, Gudat F, et al. Histological grading and staging of chronic hepatitis. J Hepatol. 1995;22(6):696-9.

23. Werle-Lapostolle B, Bowden S, Locarnini S, Wursthorn K, Petersen J, Lau G, et al. Persistence of cccDNA during the natural history of chronic hepatitis $\mathrm{B}$ and decline during adefovir dipivoxil therapy. Gastroenterology. 2004;126(7):1750-8.

24. Kozomara A, Griffiths-Jones S. miRBase: annotating high confidence microRNAs using deep sequencing data. Nucleic Acids Res. 2014;42(Database issue):D68-73.

25. Hu J, Wang Z, Liao BY, Yu L, Gao X, Lu S, et al. Human miR-1228 as a stable endogenous control for the quantification of circulating microRNAs in cancer patients. Int J Cancer. 2014;135(5):1187-94.

26. Kitson MT, Roberts SK. D-livering the message: the importance of vitamin D status in chronic liver disease. J Hepatol. 2012;57(4):897-909.

27. Poustchi H, Mohamadkhani A, Bowden S, Montazeri G, Ayres A Revill P, et al. Clinical significance of precore and core promoter mutations in genotype D hepatitis B-related chronic liver disease. JViral Hepat. 2008;15(10):753-60.

28. Lee DY, Deng Z, Wang CH, Yang BB. MicroRNA-378 promotes cell survival, tumor growth, and angiogenesis by targeting SuFu and Fus-1 expression. Proc Natl Acad Sci U S A. 2007;104(51):20350-5.

29. Maldonado RA, von Andrian UH. How tolerogenic dendritic cells induce regulatory T cells. Adv Immunol. 2010;108:111-65. 